
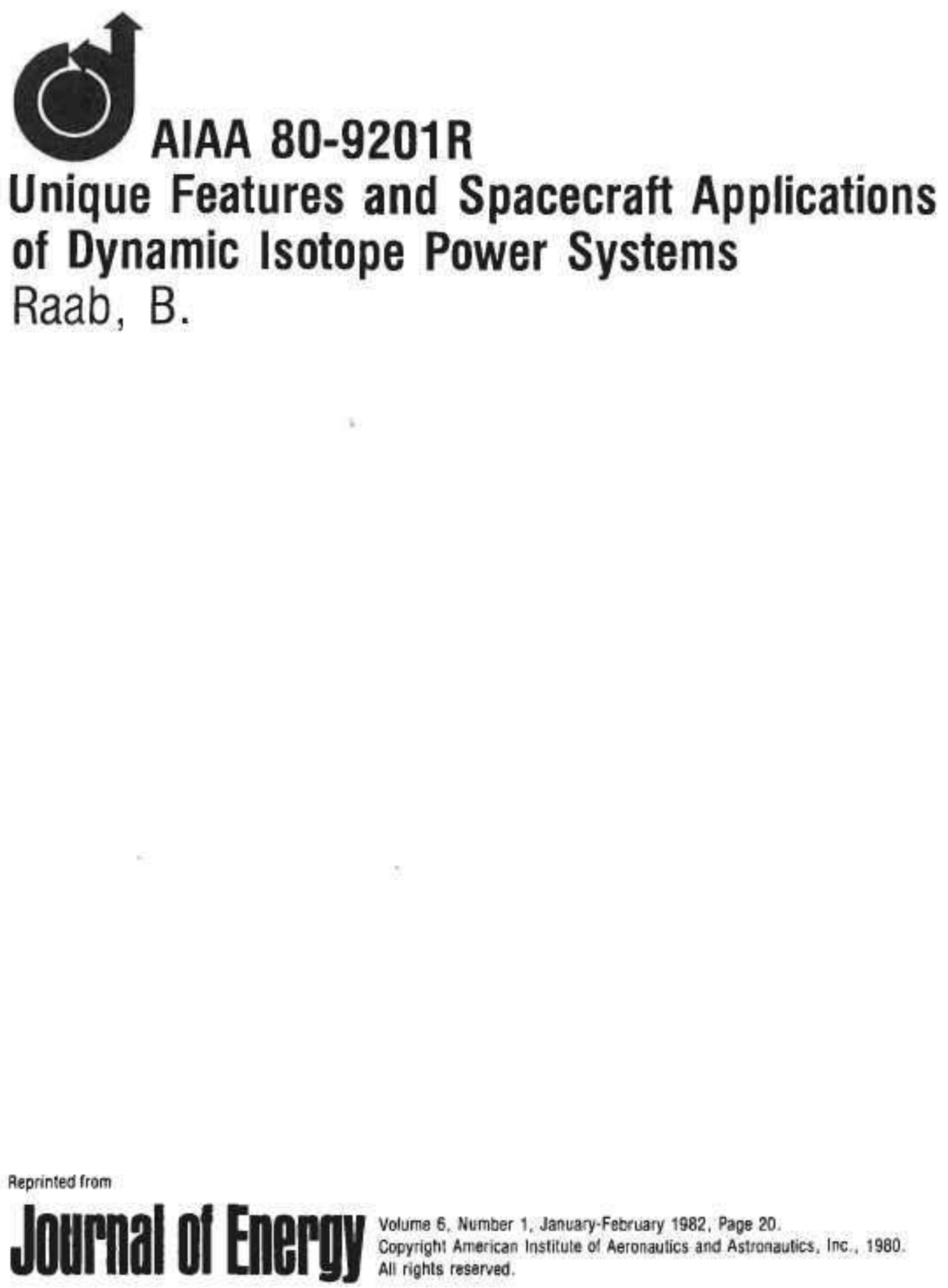



\title{
Unique Features and Spacecraft Applications of Dynamic Isotope Power Systems
}

\author{
Bernard Raab* \\ Fairchild Space \& Electronics Company, Germantown, Md.
}

\begin{abstract}
The dynamic isotope power system represents the most recent attemipt to develop a heat-engine generator for space dlectric power. A major objective in this most recent effort was to increase the power and to reduce the cost of nuclear space power systems to the point where the unique features of this power source could be brought to bear for Earth-orbit missions which could benefit therefrom. This objective was largely achieved; both weight and cost of the dynamic isotope systems are comparable to solar power systems. The dyamic isotope power system, designed for spacecraft requiring prime power in the 500-2000 W range, has been successfully built and graund tested. A number of studles, summarized berein, have demonstrated the advantages of using such a power system instead of the conventional solar system for a vuriety of Earth-orbit missions. These advantages stem from the unique nature of the dynamic isotope system, different in kiad from solar power systems. As a result, in many cases, the spacecraft design ean be significaltly simplifted and more closely harmonized with mission requirements. This overall advantage can be crucial in missions which have stringent pointing, stability, viewing, and/or positioning requirements.
\end{abstract}

\section{Introduction}

$\mathbf{S}^{1}$ INCE 1972, when the United States Atomic Energy Commission began to reconsider the development of radioisotope-fueled dynamic heat engines (i.e., closed-cycle turbine-alternator systems) for a number of candidate military and civilian space missions, Fairchild Space \& Electronics $\mathrm{Co}_{\mathrm{O}}$. and others have studied spacecraft integration and design interfaces which make optimum use of the unique features of such power systems. Since 1975, the U.S. Energy Research \& Development Administration and its successor, the U.S. Department of Energy has been pursuing the development of the organic Rankine dynamic isotope power system (DIPS). As this development program has now fesulted in the successful ground operation of the DIPS, it is useful to review the unique and unusual capabilities of this power system in the context of mission requirements and spacecraft designs.

In the past, space isotopic power systems have been available only in the form of radioisotope thermoelectric generators (RTG). Because of the relatjvely low conversion efficiencies of these devices $(5.7 \%)$, RTGs have generally been limited to missions requiring less than $500 \mathrm{~W}$. Although a number of Earth-orbit RTG applications have been successfully flown, their high cost relative to solar-array power has tended to keep their primary application to outer-planet missions, where the cost and weight of solar-array power have been prohibitive. The higher efficiency DIPS $(15-20 \%)$, has been pegged initially for the power range of $500-2000 \mathrm{~W}$. although these are not the limits of its capability. Economy in the use of costly radioisotope fuel (Pu-238) is an obvious advantage of the DIPS. The prospect of recovery and reuse of the radioisotope fuel via the Space Shuttle could further improve the economic potential of this approach for Earthorbit missions.

The advantages of DIPS-powered spacecraft designs tend to become more significant in missions which place the most stringent requirements (defined in more detail below) on conventional spacecraft.

Presented as Paper 80-9201 at the 15th Intersociety Energy Conversion Engineering Conference, Seattle, Wash., Aug. 18-22, 1980; submitted Ott. 6, 1980; revision received Aug. 27, 1981. Copyright है American Institute of Aeronautics and Astronautics, Inc., 1980. All rights reserved.

- Technical Staff Specialist. Member AlAA.
The use of solas power usually brings with it requirements for mechanical or physical orientation; additional deployments; possible blockage of sensors, thrusters, and/or antenna beams; batteries (and their control systems); attendant thermal control requirements; and vulnerability to trapped radiation (natural as well as enhanced) and incident laser radiation. While these requirements and limitations are normally accommodated at reasonable cost in most Earthorbiting spacecraft, they become more and more difficult and costly and are sometimes quite impractical to accommodate in spacecraft that must provide for high-level mission requirements as well. In most of these cases, nucleat power can offer an advantageous design alternative.

\section{A Brief History of Dynamic Space Power Systems}

It is interesting to note that the earliest effort to develop an isotopic space generator was directed toward a dynamic heatengine system.1 In March 1956, the Atomic Energy Commission contracted with the Martin Company, Baltimore, for the development of a radioisotope-fueled space power unit. A powerplant of $500 \mathrm{~W}$ for a 60 day mission was specified and a subcontract was let to Thompson Products, Cleveland, for a mercury Rankine cycle turbogenerator, designated SNAP-1. At the same time, Martin Company investigated thermionic and thermoelectric converters. Thermoelectric devices quickly proved themselves more practical technologically, leading to the cancellation of the SNAP-1 program. In contrast with the ambitious $500 \mathrm{~W}$ goal of the SNAP-1, the earliest thermoelectric generator, SNAP-3, produced only $21 / 2 \mathrm{~W}$. This modest beginning heralded the development of a continuing series of such thermoelectric generators, ranging in power up to $150 \mathrm{~W}$ each. The latest version of this series, for the two spacecraft of the International Solar Polar Mission, is designed to produce $290 \mathrm{~W}$ at the start of the planned 1986 launch.

Mercury Rankine systems continued to be developed, but for much higher power reactor systems: SNAP- $2(3 \mathrm{~kW})$ and SNAP-8 (30-60 kW). In 1965, the NASA Lewis Research Center began development of a Brayton cycle power system, designed for the $2-10 \mathrm{~kW}$ range. In the meantime, groundbased Rankine cycle systems of relatively low power were successfully developed by substituting an organic fluid $(e, g$. . Dowtherm) for the more traditional water-steam working fluid. The prospect of a space power organic Rankine system was then advanced. This would operate at low maximum 
temperature (e.g., $350^{*} \mathrm{C}$ ) and was expected to result in fewer materials and corrosion problems than had been experienced with the liquid-metal systems.

Following a period of competing development of both Brayton and organic Rankine systems in the mid-1970s, the Department of Energy selected the Rankine system for prototype development. Several of the systems application studies reported herein were based on both Brayton and Rankine eycle power systems as they were conceived at the time the studies were conducted. In general, the differences between them were not significant when compared against solar-array/battery power in the context of total spacecraft design. In fact, one of the important conclusions of our mission application studies was that no strong discriminator between Brayton and Rankine systems could be identified on the basis or mission requirements or spacecraft integration factors.

Although the Brayton system demonstrated a higher conversion efficiency, as predicted, the decision in favor of the Rankine system was based mainly on the perception of relative reliability and technology readiness as these were judged in 1978. The differences between Brayton, Rankine, or other possible nuclear power systems will not be reviewed in this paper. However, the parameters of system cost and weight of the DIPS as compared to solar-array/battery systems will be discussed in the next section, followed by a discussion of the impact of the angular momentum of the DIPS on spacecraft design.

The prototype development program of the DIPS ran for two years, 1978-80, under a DOE contract to Sundstrand Energy Systems of Rockford, III. ${ }^{2}$ A prototype system was built and successfully operated at full design output power $(1300 \mathrm{~W})$ and at $18 \%$ efficiency $(120 \mathrm{~V}$ ac output) for over $2000 \mathrm{~h}$. However, the goal of a long-term unattended and uninterrupted test was frustrated by various problems with a peripheral but nonetheless vital component: the noncondensable gas separator. This unit, of a sophisticated new design needed for $0 \mathrm{~g}$ unattended space operation, could not be adequately developed in the time allotted for this program.

\section{Cost and Weight of Solar and Nuclear Power Systems}

The advantages of dynamic isotope power systems which are described herein do not depend on the achievement of substantial, or even any, reductions in system cost and/or weight as compared to a solar-powered design, although frequently one or both are indeed achievable. Rather, these are advantages in kind, inherent to the fundamentally different natures of these two power systems. Nevertheless, a brief review of the relative status of solar and nuclear systems in these very basic parameters is useful.

In comparing the weight and cost of DIPS to solar power systems it is important to recognize that, in general, the nuclear system can be sized for $25-50 \%$ lower power than a solar system designed for the same mission. For example, a low-Earth-orbit (LEO) mission requiring $2 \mathrm{~kW}$ for $5 \mathrm{yr}$ will typically specify a solar array which is capable of producing approximately $4 \frac{1}{2} \mathrm{~kW}$ at the beginning of the mission. The excess power is required for battery charging and to compensate for array degradation over the life of the mission. The DIPS power curve will follow the radioisotope decay curve with time, so that power would decline some $4 \%$ over $5 \mathrm{yr}$. Thus, a DIPS of $2.1 \mathrm{~kW}$ would correspond to a solar array of $4.5 \mathrm{~kW}$ in this example. Nor is this necessarily an extreme case; certain orbits or environments can result in greater solar array degradation rates. On the other hand, geosynchronous (GEO) orbits will require somewhat less battery charge power and reserve for degradation. In GEO, therefore, a $25 \%$ reduction in output specification for the nuclear system is typical.

Weight comparisons are necessarily approximate unless these are done on a mission specific basis with a fixed design freeze date. Current solar/battery systems typically range 4 -
Table 1 Cost range, 1980 dollars, in millions

\begin{tabular}{crrr}
\hline \hline \multirow{2}{*}{$\begin{array}{c}\text { Peak mission } \\
\text { power, } \mathrm{kW}\end{array}$} & \multicolumn{2}{c}{ Solar } & \multicolumn{1}{c}{$\begin{array}{c}\text { Nuciear } \\
\text { DIPS }\end{array}$} \\
\cline { 2 - 3 } & LEO & GEO & \\
\hline 1 & $2-4$ & $11 / 2-3$ & $\begin{array}{c}41 / 2-81 / 2 \\
2\end{array}$ \\
\hline \hline
\end{tabular}

$12 \mathrm{~W} / \mathrm{kg}$ (LEO-to-GEO), with improvements predicted for the coming decade leading to specific power figures ranging $10-30 \mathrm{~W} / \mathrm{kg}$.

Weight of the DIPS in the range of $500-2000 \mathrm{~W}$ is relatively invariant for the conversion equipment; only the number and/or fuel loading of heat sources and the radiator size will vary significantly. A prototype system mass of $216 \mathrm{~kg}$ was demonstrated at $1300 \mathrm{~W}$, corresponding to $6.0 \mathrm{~W} / \mathrm{kg}$ and projected to approximately $8 \mathrm{~W} / \mathrm{kg}$ at $2 \mathrm{~kW}$. Considering the $25-50 \%$ power requirement differential, this corresponds to solar power systems of $9-16 \mathrm{~W} / \mathrm{kg}$. Thus the DIPS will be typically lighter than current solar power systems in the 1-2 kW range, especially for LEO applications, and potentially heavier than future solar power systems, especially for GEO applications.

The previous weight comparison deals with the power subsystem alone. Frequently, reductions in the mass of other subsystems may be realized by the nuclear spacecraft design. The Deep Space Surveillance System, discussed below, is a good example of such a case, where considerable simplication (and mass reduction) of the spacecraft was achieved.

With regard to cost, solar power systems fall typically in the range of \$1-2 million (1980) per kilowatt. ${ }^{3}$ The DIPS recurring cost has been estimated at \$1.5-2.5 million per copy, excluding radioisotope fuel. Encapsulated fuel costs may range at $\$ 500-1000$ per watt (thermal), depending on production quantities. Combining these parameters with an $18 \%$ DIPS efficiency and including the power requirement differentials discussed previously, the cost ranges shown in Table 1 result for peak mission power requirements of 1 and 2 kW.

Thus, solar power is most likely to retain a cost advantage, particularly for GEO missions, while DIPS power will be most cost-competitive for LEO missions, particularly at the higher end of the power range. It should be noted that the weight improvements previously projected for solar power will be achieved at the expense of increased cost for these power systems, while the overall system simplifications which may be achievable with nuclear power will reduce the cost of other (nonpower) subsystems.

The major conclusion to be drawn from these considerations is that cost and weight should be compared properly on an overall system basis rather than on the basis of the power subsystems alone. The historically decisive cost advantage enjoyed by solar-array power in Earth-orbit missions when compared to RTG power has not been completely obviated by the advent of DIPS; rather, the gap between them has been closed to the point where other considerations, such as those discussed in this paper, may be decisive.

\section{Angular Momentum, Vibration, and Reliability}

The angular momentum of the DIPS combined rotating unit (CRU) is not insignificant: $17.6 \mathrm{ft}-\mathrm{lb}-\mathrm{s}$. A lesser angular momentum may be contributed by the working fluid in its circulation about the system, particularly in the radiator which is likely to be at the greatest distance from the system center of mass. This contribution, typically less than $10 \%$ of that of the CRU, may be used by the system designer to enhance or to partially cancel the angular momentum of the CRU. Clearly, the method of integration of DIPS into a spacecraft must account for this angular momentum, both steady-state and possible transient variations. 
Earth-orbiting spacecraft fall generally into two attitudestabilization types: zero angular momentum and bias angular momentum. In zero-momentum spacecraft, a group of three or four momentum wheeis (e.g., three orthogonal plus one skewed for partial redundancy) is typically mounted within the spacecraft. These are spun up or down fairly continuously. to keep the spacecraft pointed in the desired direction. (Of course, once one or another of the wheels is spinning, the spacecraft is no longer totally free of angular momentum.)

Momentum wheels of $5-15 \mathrm{ft}-\mathrm{lb}-\mathrm{s}$ at maximum rated speeds are fairly common for spacecraft of several thousand pounds. In a larger class, the NASA Space Telescope (ST), scheduled for 1985 launch, uses four momentum wheels of $195 \mathrm{ft}-\mathrm{lb}-\mathrm{s}$ each in a $20,000 \mathrm{lb}$ spacecraft.

In a spacecraft the size of ST, the normal attitude control system would compensate for the DIPS angular momentum automatically. Nevertheless, it is probable in such a case, and most likely in the more common smaller spacectaft, that a separate fixed-speed momentum wheel would be provided, oriented with its momentum vector coaxial to that of the CRU. and counter-rotated to effectively cancel its angular momentum. The spacecraft momentum wheel system would then be free to respond to the usual external torque inputs, to which would be added the small transient input which may be allowed by the DIPS control system. The DIPS control system is designed to keep CRU speed constant, responding to load variations by switching in parasitic loads. During ground testing, measured speed variations were well within $\pm 1 \%$. Such variations would be readily compensated for by the spacecraft control system.

Thus, the counter-rotating momentum wheel, designed and procured to the same reliability specifications as those applied to the other standard momentum wheels, is a straightforward approach to the integration of DIPS into zero-momentum spacecraft. Redundancy may be readily achieved in this counterwheel by specifying redundant motor windings for the drive torque motors. Extensive space experience with momentum wheels shows that the sealed bearings and mechanical/structural elements are extremely reliable. The penalty of the additional (fixed speed) momentum wheel to the system in mass $(15-25 \mathrm{lb})$ and cost $\left(\$-10^{4}-10^{5}\right)$ would be minimal.

Such a counterwheel may not be required in all zeromomentum cases. For example, in the nuclear GPS spacecraft described below, the DIPS momentum is cancelled by a slow counter-rotation of the entire spacecraft, which yields important system benefits. In this case the availability of the DIPS momentum saves the weight and cost of an internal wheel which could achieve the same result.

In bias-momentum spacecraft, a fixed angular momentum vector is deliberately introduced along an axis which it is desired to stabilize in space. For a typical Earth-oriented spacecraft, this is almost always the pitch axis. A sun-oriented spacecraft may introduce such a vector along the spacectaftsun line, so as to "stiffen" that axis against small perturbing torques.

The bias momentum may be introduced either by spinning the entire spacecraft, or a major portion of it, in the desired direction (the familiar "spinner" spacecraft) or by using an internal quasifixed-speed momentum wheel similar to that previously discussed. In the spinner spacecraft much larger angular momenta are achievable $\left(>10^{2} \mathrm{ft}-\mathrm{lb}-\mathrm{s}\right)$ than can be realized with typical momentum wheels, because of the large moment of inertia of the rotating body. In such a case, the DIPS momentum would be a minor addition to (or subtraction from) the body momentum. Its orientation, however, would have to be carefully aligned coaxial to that of the body momentum 50 as not to introduce orthogonal components which might cause nutations of the spacecraft spin vector.

In those cases where a bias momentum is established by an internal wheel, so that the spacecraft body need not spin, the DIPS could be used in place of, or in augmentation of, this wheel. This would be the practical converse of the added wheel used to counter the DIPS momentum in zeromomentum systems. The weight and cost penalties incurred in those systems would be weight and cost benefits in this system. In the internal bias-momentum casc, a small coaxial vernier wheel may have to be provided to correct for the small control band variations of the DIPS.

In summary, the DIPS angular momentum can be either used beneficially or cancelled as desired. In no case studied to date has it presented any insurmountable or even unusual control problem or propulsion requirement, at least at the present level of conceptual design.

An area of remaining concern in this connection is the question of vibration. The combined rotating unit must be carefully and precisely balanced. Nevertheless, a certain amount of residual vibration is inevitable. In the ground demonstration testing, instrumented with sensitive accelerometers, a vibration level of $0.2 \mathrm{~g} \mathrm{rms}$ at CRU speed $(550$ $\mathrm{Hz}$ ) was measured on the CRU housing. Isolation mounts designed for $10 \mathrm{~Hz}$ cutoff were employed on the mounting legs to the baseplate. Such mounts typically reduce transmission at $550 \mathrm{~Hz}$ by many orders of magnitude. Vibration measurements on the hard-mounted baseplate were not practical in the ground demonstration. In general, steadystate excitations at such relatively high frequencies would not be expected to be troublesome to sensor systems, particularly if the source can be mechanically isolated.

A space test of the DIPS would be required to definitively settle this question and several other such residual concerns, including that of long-term reliability in $0 \mathrm{~g}$. The fact that the DIPS has a high-speed rotating component, unlike the more familiar RTGs or solar arrays, does not automatically compromise its reliability. For example, the high-speed angular-momentum wheels previously discussed are used routinely and in multiples in many spacecraft and have been developed to a state of very high reliability. Nevertheless, the DIPS is a complex system of many components which must all operate nominally for the system to work. Although initial reliability estimations at Sundstrand have shown a $10 \mathrm{yr}$ reliability figure in excess of 0.9 , such reliability must ultimately be demonstrated in one or more space tests before the DIPS can be accepted for operational mission applications. Such space testing is not now scheduled.

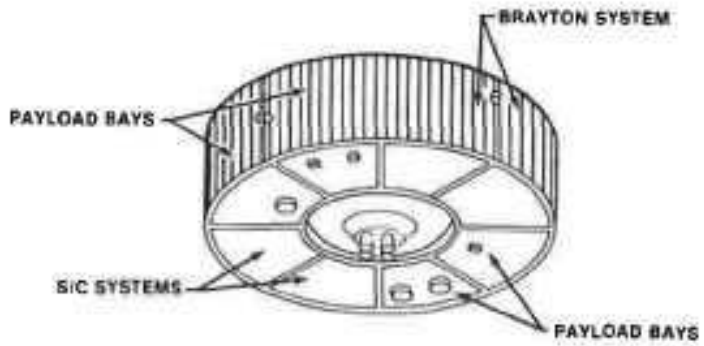

Fig. 1 DIPS-powered standard spacecraft (early Fairchild version, 1973).

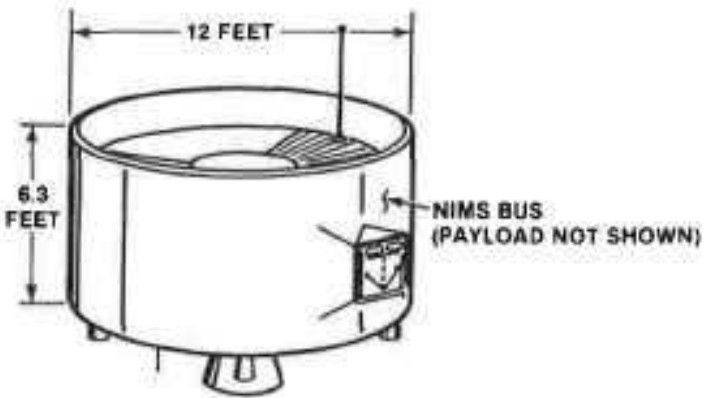

Fig. 2 Nuclear-integrated multimission spacecraft (NIMS), 1979 version. ${ }^{6,7}$ 
Table 2 Key features of DIPS-powered spacecrafi

\begin{tabular}{|c|c|c|}
\hline Mission & Key features & Key consequences. \\
\hline Multimission spacecraft & $\begin{array}{l}\text { Independence of sun angle } \\
\text { Pumped coolant loop }\end{array}$ & $\begin{array}{l}\text { Universal orbit/altitude capability } \\
\text { Power plus thermal control for payload are standard functions }\end{array}$ \\
\hline GPS/Naystar & $\begin{array}{l}\text { Pumped coolant loop } \\
\text { Pseudospherical design }\end{array}$ & $\begin{array}{l}\text { Improved ephemeris predictability } \\
\text { Excellent thermal control }\end{array}$ \\
\hline DSSS & Elimination of sun tracking requirement & $\begin{array}{l}\text { Monolithit spacecraft } \\
\text { Improved stability } \\
\text { Simplified design } \\
\text { Lower weight and power }\end{array}$ \\
\hline Landsat/Mapsat & $\begin{array}{l}\text { No deployed array } \\
\text { Short TDRS anterina boom }\end{array}$ & $\begin{array}{l}\text { Improved vibration response } \\
\text { No TDRS antenna blockage }\end{array}$ \\
\hline
\end{tabular}

Table 3 Unpredictable disturbances to solar-powered spacecraft ephemerides

\begin{tabular}{|c|c|c|}
\hline No. & $\begin{array}{l}\text { Operating } \\
\text { force }\end{array}$ & Nonrepetitive causal factor \\
\hline 1 & $\begin{array}{l}\text { Solar } \\
\text { pressure }\end{array}$ & $\begin{array}{l}\text { Orientation of spacecraft surfaces with different } \\
\alpha \text { and } \epsilon \text { to sun }\end{array}$ \\
\hline 2 & $\begin{array}{l}\text { Solat } \\
\text { pressure }\end{array}$ & $\begin{array}{l}\text { Shadowing of spacecraft surfaces by protrusions, } \\
\text { c.g., antennas, thrust cone }\end{array}$ \\
\hline 3 & $\begin{array}{l}\text { Solat } \\
\text { pressure }\end{array}$ & $\begin{array}{l}\text { Variations in louver blade angles causing variable } \\
\text { solar reflections }\end{array}$ \\
\hline 4 & $\begin{array}{l}\text { Thermal } \\
\text { radiation }\end{array}$ & $\begin{array}{l}\text { Variations cassed by independent operation of } \\
\text { thermal control louvers }\end{array}$ \\
\hline 5 & Impulse & Gas leakage or outgassing \\
\hline
\end{tabular}

\section{Candidate Missions of Interest}

The earliest of the previous studies dealt with the design of a multimission spacecraft for the economic benefits it would produce (Fig. 1). ${ }^{4}$ These studies were updated in 1978-79 in a study which illustrated the advantages of using the thermally integrated design approach ${ }^{5}$ in a multimission spacecraft (Fig. 2). 6,7 Such a spacecraft provides all of the necessary housekeeping functions, including all prime power and payload thermal control. These last two functions are not notmally (or readily) available in a solar-powered multimission spacecraft.

Throughout these and other studies, certain key and unique features of the nuclear-powered designs have emerged, such as: the ability to fly in any orbit without modification, the ability to configure and to orient the spacecraft in much closer conformance with mission requirements, and the ability to eliminate flexible appendages and moving mechanical assemblies which are common to a large number of solarpowered spacecraft.

These advantages apply to many missions, but most strongly to a class of missions which have either one or a combination of the following stringent requirements:

1) Highly accurate knowledge of spacecraft position.

2) Very precise control of spacecraft orientation.

3) Extremely stable plat form for sensor mounting.

The Global Positioning System (GPS Navstar) mission carries only the first of these requirements. Onboard knowledge of spacecraft position to within a few meters is required at all times. A 1977 Fairchild study ${ }^{8}$ revealed the advantage of a nuclear-dynamic integrated design for this application, in which the unpredictable portion of spacecraft ephemeris drift is reduced by an order of magnitude or more compared to the conventional solar-powered design.

The Deep Space Surveillance System (DSSS) is an example of a mission in which requirements 2 and 3 appear simultaneously. A $1975-76$ study ${ }^{9}$ conducted at Fairchild under ERDA sponsorship revealed how a nuclear-dynamic power system could enhance the performance of this mission with a spacecraft of inherently simpler and more practical design than the solar-powered alternative.
Tuble 4 Onboard clock frequency stability

\begin{tabular}{cccc}
\hline \hline \multirow{2}{*}{$\begin{array}{c}\text { Frequency } \\
\text { standard }\end{array}$} & $\begin{array}{c}\text { Frequency } \\
\text { stability, } \\
\text { Af/f/day }\end{array}$ & \multicolumn{2}{c}{ Range error buildup } \\
\cline { 4 - 5 } & $\mathrm{m} / \mathrm{h}$ & $\mathrm{m} / \mathrm{day}$ \\
\hline $\mathrm{Rb}$ & $10^{-12}$ & 1,1 & 26 \\
$\mathrm{Cs}$ & $10^{-13}$ & 0.1 & 2.6 \\
$\mathrm{H}_{2}$-maser & $10^{-14}$ & 0.01 & 0.26 \\
\hline \hline
\end{tabular}

Most recently, missions having alt three of the requirements have become known. Some examples are the advanced Defense Meteorological Satellite-Block 6, Landsat-D, and the Stereosat/Mapsat, which combines an operational Landsattype mission with a highly accurate three-dimensional Earthmapping mission. Some of the initial considerations of a nuclear-powered approach to the Landsat-type mission are described.

The unique features of a nuclear spacecraft design which are important in each of these cases are summarized in Table 2. These are, in general, different for each of the missions studied, as are the beneficial consequences which flow therefrom, which result from the greater freedom in design which the DIPS allows. Each of these will be described in more detail below.

The ultimate selection between a solar or a nuclear design approach for a particular mission must, of course, include such other factors as cost, reliability, liftetime, schedule, and risk. The demonstration of reliability and lifetime within a reasonable cost and schedule capability is the major task remaining for DIPS. However, its unique technical capabilities make it a promising candidate for many missions of great future importance.

\section{Global Positioning Sysiem (GPS)}

The 1976-77 Fairchild study was directed toward achieving improvements in a number of critical parameters of the existing solar-powered space vehicle: 1) inereased power to user, 2) increased satellite lifetime, 3) improved system accuracy between satellite updates from the ground.

The last parameter is a function of two main factors: 4) the stability of the onboard frequency standard, and 5) the predictability of the satellite ephemeris into future time. The predictability of the satellite ephemeris is, in turn, a function of the modelability of the satelfite design with regard mainly to solar pressure effects.

To the extent that vehicle ephemeris drift can be modeled and predicted, the ground user will be able to compensate for this drift by the application of perturbation cocfficients which will be transmitted by the satellite along with the Keplerian orbit elements. Such important disturbances as geodetic variations in the gravitational field of the Earth and the major solar pressure effects can be modeled and predicted with good accuracy. However, there are significant disturbances which cannot be modeled or which vary so much or so unpredictably from day to day that they will result in unpredictable changes 
in satellite ephemerides and hence time-dependent degradation in system accuracy. Among the more significant of the unpredictable disturbances that apply to the existing solar-powered spacecraft are those shown in Table 3 .

The phenomena noted in items 1 and 2 of Table 3 do, of course, repeat on an annual basis and change only slowly from day to day. However, the extent to which they repeat is governed by the accuracy of the control system and the extent to which the satellite can be physically modeled.

It has been estimated by the GPS program office that these residual errors will ultimately result in an unpredicted ephemeris drift of the order of $1.25 \mathrm{~m} /$ day. To this error must be added the equivalent error due to uncorrected drift of the onboard frequency standard. Three frequency standards based on different technologies are projected to be available for the GPS satellites. These are shown in Table 4 with the order of magnitude of the expected drift rate of each type. Clearly, with the use of a rubidium standard, user-calculated position error would be clock-dominated, while a cesium standard would result in roughly comparable errors from both sources. Significant improvement in the stability of the cesium standard, or the introduction of the ultimate hydrogen-maser standard, however, would be incompatible with the continued use of the current solar-powered satellite.

It is obvious that by eliminating the solar arrays, a nuclear spacecraft would have a positive impact on ephemeris predictability simply by reducing the projected area and hence the absolute magnitude of the total solar force. Perhaps not as obviously, however, a nuclear spacecraft can have a substantial impact on all of the disturbances listed in Table 3. Elimination of the sun-pointing requirement of the solar arrays introduces a number of design options that can substantially improve or eliminate almost all of the listed disturbances. This requirement strongly influenced the design approaches explored and the one ultimately selected.

The ideal spacecraft designed for ephemeris predictability would be spherical with uniform solar reflectivity. The unique feature of the DIPS is that it enables a spacecraft design that resembles this ideal in many essential features. It also enables the mission to be performed with a slow yaw rotation of the spacecraft to further enhance this predictability factor.

Consequently, a nuclear-powered design was selected (Fig. 3) that would simplify the external characteristics of the space vehicle in shape, in surface properties, and in operating mode so as to improve the modelability of the spacecraft. In addition to reducing the absolute magnitude of projected area. the introduction of a nuclear power system can allow the design of the spacecraft with simple external configuration, with minimum variations in surface material and with the possibility for rotating the spacecraft in orbit. The latter factor permits further improvement of orbit predictability, as well as certain other benefits, because of the averaging effect of the rolation.

The desire for a highly temperature-controlled environment for the frequency standards led to the selection of a highly integrated design approach in this case. Here, the electronic payload equipment is mounted within the power system radiator and is cooled by heat-pipe-assisted conduction directly to the working fluid of the power system. The mechanical and thermal design approaches are illustrated in Fig. 3.5 Despite the high order of integration achieved thereby, the equipment module and power system module are readily separable for assembly and test prior to system final assembly.

The selection of a thermally integrated design, in which the skin of the spacecraft acts as the heat radiator for both the power system and all of the spacecraft electronic equipment, enables the spacecraft to be designed with all surfaces uniformly coated and acting as portions of the radiator. This design approach also leads to a steady baseplate temperature for the frequency standards and to a spacecraft that is naturally hardened against a laser threat. ${ }^{6}$

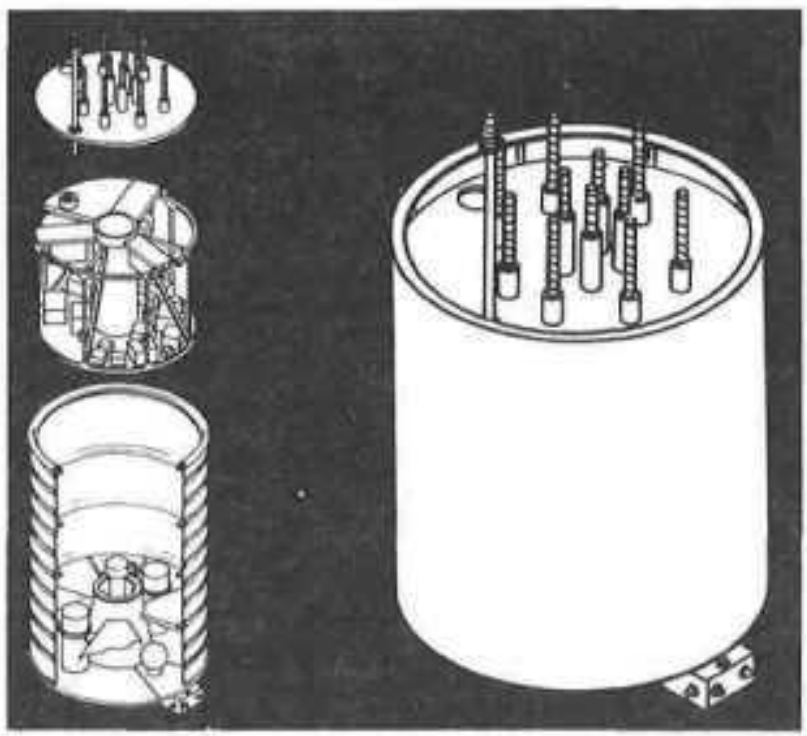

Fig. 3 Nuclear GPS spacecraft.

Table 5 Unpredictable disfurbances to nuclear-integrated spacecraft ephemerides

\begin{tabular}{ccc}
\hline No. & $\begin{array}{c}\text { Operating } \\
\text { force }\end{array}$ & Nonrepetitive causal factor \\
\hline I & $\begin{array}{c}\text { Thermal } \\
\text { radiation }\end{array}$ & Misestimation of surface temperatures \\
2 & $\begin{array}{c}\text { Solar } \\
\text { pressure } \\
\text { Impulse }\end{array}$ & $\begin{array}{c}\text { Spacecraft misalignment in principal axis } \\
\text { Misaligned or mismatched propulsion } \\
\text { system jers }\end{array}$ \\
\hline \hline
\end{tabular}

The yaw rotation of approximately $1 \mathrm{rpm}$ is enabled by the azimuth-independent nature of the GPS signal. This slow spacecraft rotation is used to counter the rotational momentum of the DIPS rotating group and results in a substantial reduction in the importance of the solar pressure effects to the ephemeris prediction uncertainty.

The residual uncertainty of the nuclear GPS spacecraft was analyzed to be due to the three main causes shown in Table 5. The phase I GPS development satellites have demonstrated the usefulness and reliability of magnetic torquing for momentum wheel unloading in the GPS spacecraft orbits, thereby eliminating error source 3 in Table 5 from consideration.

Table 6 shows the calculated effects of the remaining error sources on the knowledge of spacecraft position in both the radial and transverse directions relative to the Earth's center. Because user position error calculations are less sensitive to transverse spacecraft position errors by factors of $5-10$ relative to radial spacecraft position errors, the transverse errors are divided by 5 and added to the radial errors on the bottom line.

Thus, the result of transitioning from a solar three-axis spacecraft to a nuclear-integrated spacecraft is to reduce spacecraft ephemerides errors by more than an order of magnitude, making this error source potentially less significant than the drift of the ultimate hydrogen maser clock. The effect on the user position error calculations, assuming a complete 24-satellite constellation, is shown in Fig. 4.

This is illustrative of the benefits which can be realized by any space system that requires highly accurate knowledge of spacecraft position only. Although the GPS satellites are intended to be updated daily while the master control station 
Table 6 Maximum orhit ephemerides errors due to unpredicted spacecraft conditions

\begin{tabular}{|c|c|c|}
\hline \multirow[b]{2}{*}{ Error source } & \multicolumn{2}{|c|}{ Etror rates, ft/day } \\
\hline & Radial & Transverse \\
\hline Thermal effects & 0.015 & 0.15 \\
\hline \multirow{3}{*}{$\begin{array}{l}\text { 1) Prediction error in temperature of } \\
\text { Earth-viewing face }=4^{\circ} \mathrm{C} \\
\text { 2) Prediction error in temperature of } \\
\text { space-viewing face }=2^{\circ} \mathrm{C} \\
\text { 3) Mean temperature difference on } \\
\text { opposite sides of cylinder due to } \\
\text { helical cooling coil }=10^{\circ} \mathrm{C}\end{array}$} & 0.010 & 0.10 \\
\hline & 0.005 & 0.05 \\
\hline & 0.00028 & 0.0028 \\
\hline \multicolumn{3}{|l|}{ Spacecraft misalignment (conical } \\
\hline rotation mode) & 0.065 & 0.13 \\
\hline \multicolumn{3}{|l|}{ 1) Alignment error $=0.5 \mathrm{deg}$} \\
\hline uniform reflectivity & 0.025 & 0.05 \\
\hline \multicolumn{3}{|l|}{ 2) Alignment error $=0.5 \mathrm{deg}$} \\
\hline nonuniform reflectivity & 0.025 & 0.05 \\
\hline $\begin{array}{l}\text { 3) Alignment error }=0.5 \mathrm{deg} \\
\text { self-shadowing effect }\end{array}$ & 0.04 & 0.08 \\
\hline Total, all effects, fu/day & 0.08 & 0.28 \\
\hline$m /$ day & 0.02 & 0.08 \\
\hline Overall, $\mathrm{m} /$ day & \multicolumn{2}{|c|}{0.04} \\
\hline
\end{tabular}

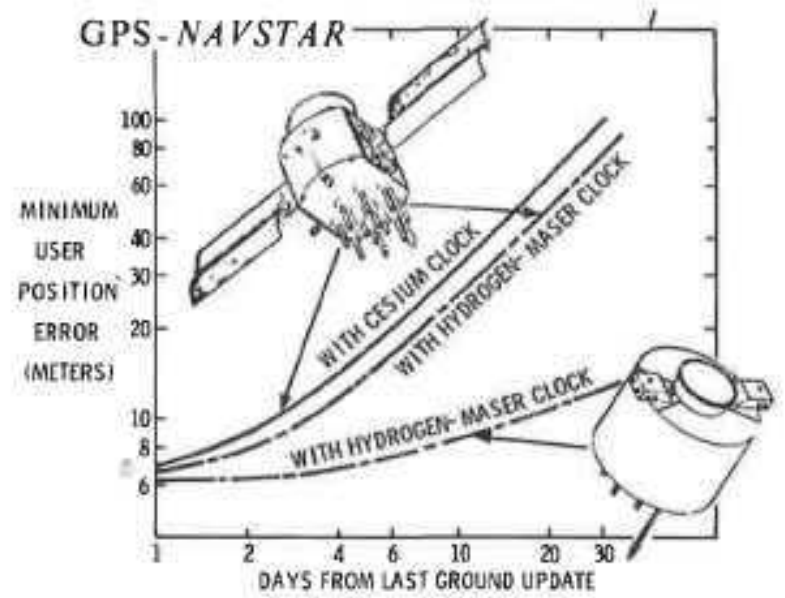

Fig. 4 GPS system graceful degradation rate depends on elock drifi and epheraeris prediciability faciors.

is operational, not every space system can afford the continuous tracking, modeling, and computational resources of the GPS program. Those systems which will rely on GPS receivers for this purpose will be vulnerable to the failure of these receivers, while the GPS system itself will be vulnerable to failure of the master control station, resulting in user accuracy degradation along the lines described by Fig. 4 .

\section{Deep Space Survelliance Satellite System}

Solar-Powered Design

The Deep Space Surveillance System (DSSS) is an example of a space-object surveillance satellite which requires a highly stable platform with very precise sensor pointing control requirements. A variety of scanning and staring motions may be required of the sensor, which may operate in either the visible or long-wave infrared (LWIR) region of the spectrum. A variety of orbits is under consideration.

This mission was reviewed in a 1977 IECEC paper. ${ }^{2}$ In its solar-powered configuration, at least three and perhaps four rotating joints are required, in addition to a very large deployed solar array (total power requirement can be as large as $4 \mathrm{kWe}$ ). In schematic configuration the solar-powered design of this spacecraft will follow the format shown in Fig. 5.

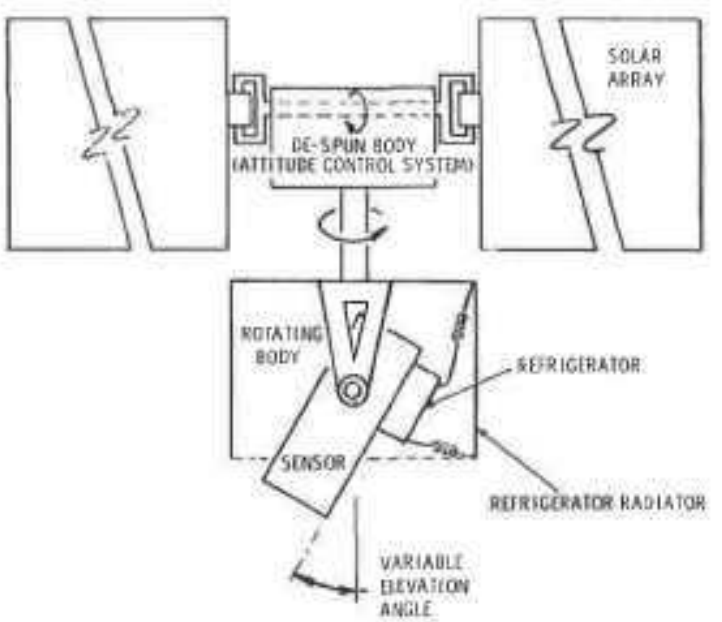

Fig. 5 Solar-powered spacecraft; basic configurution (schematic).

Although the structural dynamics of this spacecraft design has not yet been studied in depth, a design with so many rotating joints and sources of structural excitation is inimical to the achievement of the required level of spacecraft stability ( $\leq 2 \mathrm{arcsec} / \mathrm{s})$ and fine pointing control ( $\sim \operatorname{arcsec})$. (See next section on Landsat D.) A more recent study of the thermal control requirements of this spacecraft in its LWIR version ${ }^{10}$ illustrated and verified the required solar-powered spacecraft design approach (Fig. 6). Figure 6a follows the schematic layout of Fig. 5 precisely. Figure $6 \mathrm{~b}$ illustrates the contractor's conclusion that in a low-altitude orbit the (deployable) refrigerator radiator must be mounted on the despun section of the spacecraft, necessitating the development of a fluid swivel joint to duct the refrigerator coolant across the rotating joint. In the high-altitude version, a flexible coolant line is required, as depicted in Fig. 5.

\section{Nuclear Powered Design}

In the nuclear-powered design approach, both sections of the spacecraft are mounted together without intervening rotating joints. The sensor is similarly mounted in a fixed position within the spacecraft (Fig. 7). This is the so-called "monolithic" design approach in which all rotating joints are eliminated. In this case the entire spacecraft performs the 
a. HIGH ALTITUDE EQUATORIAL
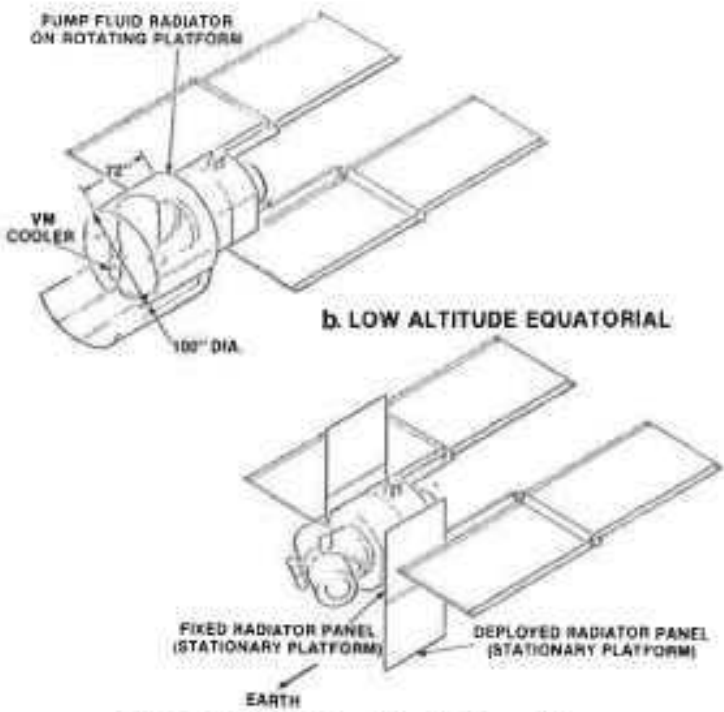

Kig. 6 DSsS designs (Vought Corp, ${ }^{10}$ ).

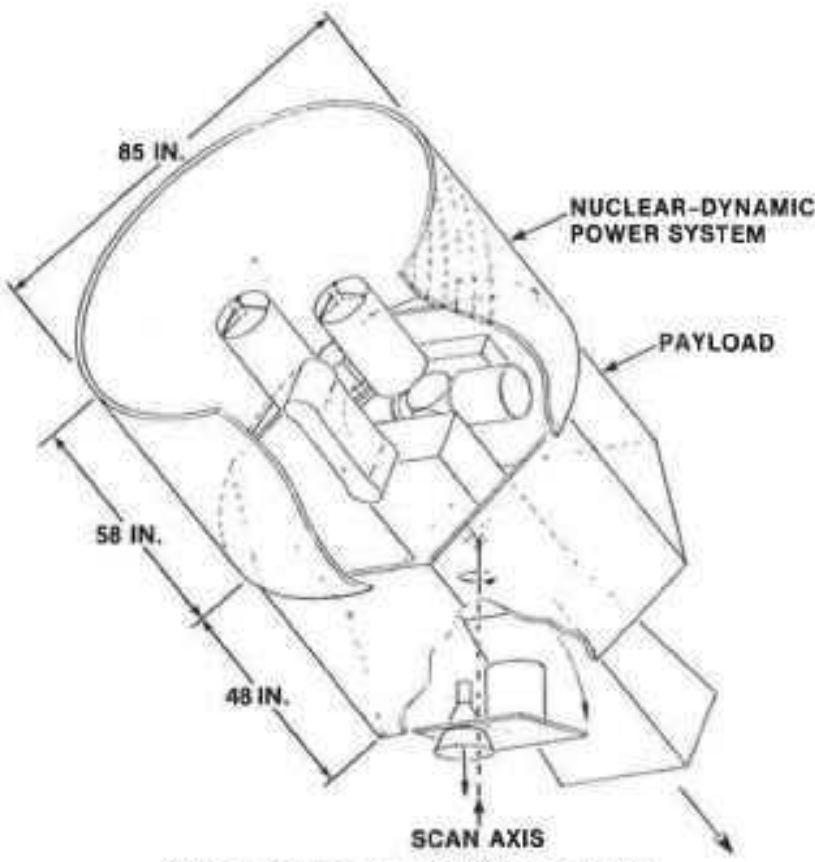

Fig. 7 Nuclear-powered DSSS spacecraft.

required motions, controlled by a small attitude control package mounted to a lower platform. This platform is oriented at all times perpendicular to the Earth's nadir and is hinged along one edge to accomplish this orientation. The hinge angle is varied, however, only when the elevation angle is to be changed and is then locked into its new position. Both attitude control equipment and Earth communications antenna are mounted onto this surface. Alternatively, this mission can be performed with control-moment gyros for attitude control.

In Ref. 9, this design approach was shown to be capable of reducing spacecraft electric power requirements by some $50 \%$ and reducing spacecraft weight by some $20 \%$. Its superior structural dynamics and stability characteristics compared to the multijointed solar design are evident qualitatively, although neither design has been analyzed to date. Table? summarizes the advantages of the nuclear DSSS design.
Table 7 Advantages of nuciear spacecraft for DSSS

1) Flies in any orbit without modification

2) Performs continuous scan, stare, or other motions

3) Insensitive to normal or enhanced Van Allen radiation

4) Nucleat and laser hard

5) Reduced visibility to optical or radar search

6) Maneuverable with minimal warning time

7) Monolithic spacecraft design

eliminates rotating assemblies

eliminates sensor gimballing

eliminates flex fluid lines, fluid swivel joints

B) No solat array deployment

9) No radiator deployment

10) No center-of-gravity stifits resulting from sensor motion

11) No batteries required for eclipse operation

12) No thermal storage required for refrigerator operation during eclipse

Table 8 Landsat-D residual error budget

\begin{tabular}{llr}
\hline \hline & \multicolumn{2}{c}{ Error. 10 } \\
\cline { 2 - 3 } \multicolumn{1}{c}{ Souree of error } & $\mathrm{m}$ & $\mathrm{s}$ \\
\hline & & \\
Ephemeris & 2.8 & - \\
Attitude & 2.8 & 0.8 \\
Spacecraft vibration & 1.0 & 0.3 \\
Others & 5.0 & - \\
\hline \hline
\end{tabular}

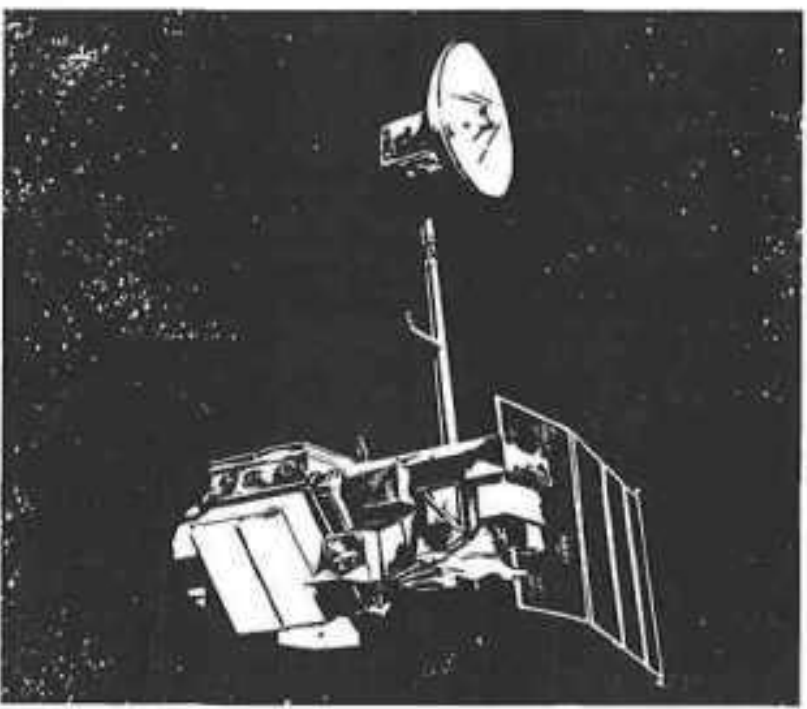

Fig. 8 Landsat-D spacecraft.

\section{DMSP-Block 6/I andsat-D/Mapsat}

These three missions combine the three stringent requirements for highly accurate position knowledge, attitude control, and sensor stability which are likely to become typical of future optical-observation missions. Of these, only the Landsat-D is a currently approved mission, now scheduled for launch in late 1982. Mapsat, now in the conccptual design study phase, will be similar to Landsat-D in most spacecraft requirements. The Landsat- $D$ therefore may be a paradigm for future missions of this type (Fig. 8).

In order to achieve the required optical performance, the Landsat spacecraft error budget in the three parameters of interest has been established as shown in Table 8. 11

The ephemeris and attitude requirements are not expected to be achieved by spacecraft equipment alone, despite the use of a GPS receiver onboard the spacecraft for the former. Fortunately, these two requirements can be finessed in the 


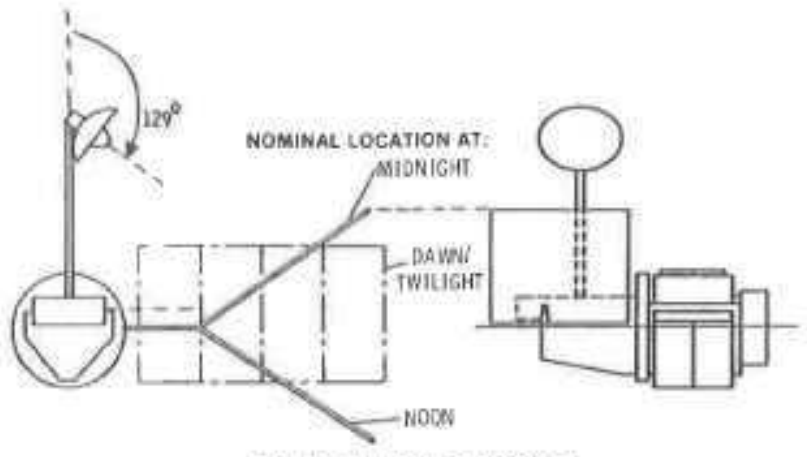

Fig. 9 Landsat-D geometry.

Landsat case by a posteriori analysis of the transmitted image data and by matching these data to known ground features. In addition, these requirements may ultimately be satisfied autonomously by only modest improvements in the onboard inertial control system and by long-range improvements in the GPS accuracy, along the lines previously indicated.

The problem of spacecraft vibration is more insidious, however, and more difficult to solve within the context of a solar-powered design. Although the problem is rarely, if ever. identified with the use of solar power, the solar arrays are implicated both directly and indirectly.

The cause of spacecraft vibration is the dynamic interaction of onboard moving elements, of which the solar-array drive is one, with a flexible body spacecraft. The major sources of spacecraft flexibility are the solar arrays and the Tracking \& Data Relay System (TDRS) antenna boom.

The latter in particular has been identified as a major source of dynamic influence on the spacecraft caused in large part by locating a relatively heavy component $(6 \mathrm{ft}$ diam antenna plus electronics) at the end of a $12 \frac{1}{2} \mathrm{ft}$ long boom. However, the length of the boom was determined by the need to prevent blockage of the antenna beam ( 5 deg clear field of view) by the solar array. The geometric situation is seen more clearly in Fig. 9, with the elevation gimbal angle of the antenna shown (azimuth angle $=400 \mathrm{deg}$ ). Despite the extension of the antenna some blockage of the beam about the midnight array position is experienced. Such extreme gimbal angles are required only during northern hemisphere winter periods, so that the overall dara loss to the mission is considered to be acceptable at this point. Clearly, however, a shorter boom would result in unacceptable daily blockage of the TDRS antenna beam, which is the main communications link of the spacecraft.

Thus, the solar array contributes to spacecraft dynamic flexibility both directly and indirectly, by its own presence and by dictating the need for a long antenna boom. Although a nuclear-powered version of Landsat has not been designed, an approach similar to the monolithic design of the DSSS shown previously would result in a more rigid spacecraft less subject to potentially damaging and image-degrading internal vibration. The potential advantages of a DIPS-powered Landsat, presumably applying as well to Mapsat, are summarized in Table 9.

\section{Summary}

The use of nuclear power results in the elimination of the sun-tracking or orientation requirement and the elimination or reduction of major deployment requirements. This leads
Tubie 9 Anticipated advantages of nuclear-powered Landsat/Mapsat

1) Reduces spacecraft vibration

2) Eliminates TDRS antenna blockage by solar arraiss

3) Eliminates thruster misalignment doe to deployments

4) Eliminates safe-hold mode reorientation requirements

5) Allows near-total freedom in spacectaft orientation for thrusting

to the unique features of nuclear power, which have profound consequences for high-requirement missions, by enabling spacecraft design to focus more directly on mission requirements without the need for also satisfying the difficult solar-array requirements. These features and consequences are summarized in Table 2.

\section{Acknowledgments}

This research was supported by the U.S. Department of Energy and its predecessor agencies, the Atomic Energy Commission and the Energy Research and Development Administration. The author acknowledges with gratitude Mr. Marcus A. Frieder of Fairchild Space and Electronics Company Systems Engineering Department for his many innovative insights and technical contributions to the work reported here,

\section{References}

'Space Nuclear Power Applientions, Hearings Before the Subcommittee on Research, Development, and Radiation of the Joint Committec on Atornic Energy, Eighty-Seventh Congress, Sept: 13, 14, and 19,1962 , U.S. Government Printing Office, Wash. D.C., 1962. $\mathrm{pp}_{-}, 301,302$.

isorenson, G.L., Niggeman, R.E., Peck, N.W., end Kenney, W.D." "The 1980 Technology Status of the Dynamic Isotope Power System," Proceedings of the 15th Intersocieiy Energy Conversion Engineering Conference, Aug. 1980, pp, $720-725$.

${ }^{3}$ Mahefky, T. Jr. "Future Space Power-The D.O.D. Perspective," Proceedings of the 15ih Intersociety Energy Conversion Engineering Conference, Aug. 1980, pp. 89-94.

${ }^{4}$ Frey, E.J. Raab, B., Schock, A., and Clirpenter, R.T. "Spacecraft Standardization through Nuclear Power," Journal of Spacecraft and Rockets, Vol. 11. Nov, 1974, pp. 741-2.

$5_{\text {Raub, B. "A Therrnally-Integrated Spacectaft Designt Approach }}$ Using Nuclear Dynamic Power Systerns," Proceedings of the 13th Intersociety Energy Conversion Engineering Conference, 1978, pp. $1678-1684$

${ }^{6}$ Kenney, W.D., Prickett, W. Z, and Krueger, E.C., "Application of the Dynamic Isotope Power System to a Multi-Mission Spacceraft," Proceedings of the $14 \mathrm{th}$ Intersociety Energy Conversion Engineering Conference, 1979 , pp. 1406-1410.

"'Dynamic 1sotope Power System (DIPS) Applications Study," General Electric Space Division, Philadeiphia, Final Rept. 79SDS4228, DOE/ET/3267-1, Noy, 1979.

"."Nuclear-Powered GPS Spacecraft Design Study." Fairchild Space \& Electronics Co., Germantown, Md., ESD-217-77/108, ERDA-NRA-3063-10, May 1977.

"Raab, B. "Nuclear Powered Infrared Surveillance Saiellite Study," Proceedings of the 12th Intersociety Energy Conversion Engineering Conference, 1977, pp. 1335-1342

"Oren, J.A. and Wiggens, C.L., "Design Analysis for Survellance Satellite Thermal Control Systems," AFFDL-TR-79-3009, Feb. 1979 .

"Bachofer, B.T., "Landsat D Case Study in Spacecraft Design," AIAA Professional Study Series. Aug. 1979. 